\title{
Dependence of the proactive behavioral effects of theta-driving septal stimulation on stimulation frequency and behavioral experience: 2. Continuously and partially reinforced running
}

\author{
MICHAEL SNAPE, GRIGORY GRIGORYAN, JOHN D. SINDEN, and JEFFREY A. GRAY \\ The Institute of Psychiatry, London, England
}

\begin{abstract}
Two experiments were conducted with Sprague-Dawley rats, chronically implanted with medial septal stimulating and subicular recording electrodes, to test the hypothesis that low-frequency electrical stimulation of the septal area, driving the hippocampal theta rhythm, has frequency-dependent proactive efects on behavior: specifically, that theta-driving stimulation at $7.5 \mathrm{~Hz}$ gives rise to tolerance for subsequent frustrative nonreward, whereas stimulation at $7.7 \mathrm{~Hz}$ sensitizes the animal to this event. After a 10-day stimulation regime (fifteen 6-sec stimulation trains at a 30-sec intertrain interval daily; $7.5 \mathrm{~Hz}$ in Experiment 1, 7.7 Hz in Experiment 2), rats were trained to run in a straight alley for food reward at 1 trial/day for 16 days on either a continuous reinforcement (CRF) or a partial reinforcement (PRF) reinforcement schedule followed by extinction; implanted controls were not stimulated but were otherwise treated identically. As predicted by the hypothesis, the partial reinforcement extinction effect (PREE; i.e., greater resistance to extinction after PRF than after CRF training) was proactively reduced by $7.5-\mathrm{Hz}$ stimulation, owing to lowered resistance to extinction in the stimulated PRF-trained animals relative to their nonstimulated controls; whereas, again as predicted, the PREE was increased by $7.7-\mathrm{Hz}$ stimulation, owing both to increased resistance to extinction in the stimulated PRF condition and reduced resistance to extinction in the stimulated $\mathrm{CRF}$ condition relative to the respective nonstimulated control groups. Thus the proactive behavioral effects of 7.5- and 7.7-Hz stimulation were opposite in sign, dependent in both cases upon the schedule of reinforcement encountered subsequent to stimulation, and consistent, respectively, with stimulation-induced tolerance for nonreward $(7.5 \mathrm{~Hz})$ or sensitization of the response to nonreward $(7.7 \mathrm{~Hz})$.
\end{abstract}

It is possible to elicit the hippocampal theta rhythm in freely moving rats by means of electrical stimulation of the pacemaker cells for the rhythm located in the medial septal area (Gray \& Ball, 1970; Stumpf, 1965). Such theta-driving stimulation induces hippocampal theta at times and frequencies determined by the experimenter, thus affording a powerful tool with which to analyze the behavioral functions of this electrical rhythm. Using this method, a number of workers have shown that theta driving alters behavior in runway (Gray, 1972), avoidance learning (Landfield, 1977; Wetzel, Ott, \& Matthies, 1977), T-maze (Deupree, Coppock, \& Willer, 1982), and leverpress (Glazer, 1974a, 1974b; Holt \& Gray, 1983b, 1985; Williams, Gray, Snape, \& Holt, 1989) paradigms. In some of these experiments, the effects of theta-driving septal stimulation have been shown to be proactive, the consequent changes in behavior being observed up to several weeks after the end of the stimulation regime (Deupree et al., 1982; Holt \& Gray, 1983b, 1985; Williams et al., 1989). Furthermore, the di-

M.S. was supported by a Science and Engineering Research Council Studentship; G.G., by the Royal Society. Correspondence concerning this article should be addressed to J. A. Gray, The Institute of Psychiatry, De Crespigny Park, Denmark Hill, London SE5 8AF, England. rection of the behavioral effects obtained in such experiments appears to depend on the precise frequency of the applied stimulation, and therefore of the elicited theta (Williams et al., 1989). Thus, in a companion paper (Williams \& Gray, 1996), we have demonstrated that, applied before acquisition of a discrete-trial fixed-ratio (FR) 5 leverpressing response, a regime of theta-driving septal stimulation at either 8.3 or $7.7 \mathrm{~Hz}$ increases the resistance to extinction of this response, whereas stimulation at $7.5 \mathrm{~Hz}$ decreases resistance to extinction.

Theoretical interpretation of the function of hippocampal theta remains controversial. The most widely accepted hypotheses allot to it a role in motor behavior (Vanderwolf, 1969) or spatial cognition (O'Keefe \& Nadel, 1978); according to a third hypothesis (Landfield, 1977), it is involved in memory consolidation. It is difficult, however, to derive predictions from any of these hypotheses concerning the likely effects of theta driving applied before the animal is ever trained on the test response, especially if this does not involve locomotion through space, as is the case with the leverpressing response used in Holt and Gray's (1983a, 1983b, 1985) and Williams and Gray's (1996; and see Williams et al., 1989) experiments. The results of these experiments, as well as those reported earlier by Gray (1972) and Glazer (1974a, 1974b), are, however, consistent with 
Williams's (1988; Williams et al., 1989) model, an extension of Gray's earlier $(1970,1982)$ hypothesis linking the theta rhythm, especially at a frequency of $7.7 \mathrm{~Hz}$, to frustration and anxiety. According to this model, theta-driving stimulation at 7.7 or $8.3 \mathrm{~Hz}$ sensitizes the animal to subsequent frustrative nonreward (Amsel, 1962, 1992), whereas $7.5-\mathrm{Hz}$ stimulation gives rise to behavioral tolerance for this event.

Application of Williams's (1988) hypothesis to the discrete-trial FR5 leverpress schedule employed by Holt and Gray (1983b) and Williams and Gray (1996) depends critically on whether this is interpreted as equivalent to a continuous reinforcement (CRF) or partial reinforcement (PRF) schedule as used in studies of running in the straight alley (Amsel, 1962). Glazer (1974a, 1974b), who first introduced the FR5 paradigm into this line of research, supposed that it was the equivalent of a CRF schedule. However, we have recently reported four experiments which rule out this assumption but are consistent instead with a functional equivalence between the FR5 paradigm and an alley PRF schedule (Williams, Gray, Sinden, Buckland, \& Rawlins, 1990). Given this equivalence, it follows that subjects experience frustration after nonrewarded responses in the FR5 paradigm as they do on a PRF schedule; and that this experience results in (1) the conditioning of anticipatory frustration to apparatus cues, and (2) the counterconditioning of such anticipatory frustration when rewards are presented (Amsel, 1962, 1992).

Consider now the effects of $7.7-$ or $8.3-\mathrm{Hz}$ theta driving stimulation (Holt \& Gray, 1983b; Williams \& Gray, 1996). Applied before acquisition of the FR5 response, this will, ex hypothesi (Williams et al., 1989), cause animals to become more sensitive to frustrative nonreward, and thus, during acquisition of the FR5 response, to develop greater conditioning of anticipatory frustration, followed by counterconditioning of a greater degree of anticipatory frustration, giving rise finally to greater resistance to extinction, as observed (Holt \& Gray, 1983b; Williams \& Gray, 1996, Experiment 1). Conversely, 7.5- $\mathrm{Hz}$ stimulation applied in the same way will render animals less sensitive to frustrative nonreward, so that they develop less anticipatory frustration during FR5 acquisition, undergo less counterconditioning, and finally show less resistance to extinction, than will unstimulated controls, also as observed (Williams \& Gray, 1996, Experiment 2).

In order to test this hypothesis with regard to stimulation at $8.3 \mathrm{~Hz}$, Williams and Gray (1996, Experiment 3) varied the temporal relationship between the period of stimulation and acquisition of the FR5 response. They argued that, if stimulation at this frequency sensitizes animals to subsequent nonreward, and if nonreward is not encountered until extinction commences, then rather than increasing resistance to extinction, as it does when applied before acquisition (Holt \& Gray, 1983b; Williams \& Gray, 1996, Experiment 1; Williams et al., 1989), it should now reduce resistance to extinction. This, indeed, was the result obtained. Within Williams's (1988) hypothesis, interpretation of this result supposes that the differing behavioral effects of theta-driving stimulation applied before and after FR5 acquisition, respectively, are due to experience after the stimulation period is over-that is, whether or not acquisition of the FR5 response is interpolated between this period and the final behavioral test of extinction. However, the design of Williams and Gray's (1996) Experiment 3 leaves open the alternative possibility that the effects of theta driving are a function of experience $b e$ fore the period of stimulation - that is, whether or not the stimulation is preceded by FR5 acquisition. An effect of the latter kind might occur, for example, if theta driving affected memory consolidation, as proposed by Landfield (1977).

In order to test Williams's (1988) hypothesis without running into this problem of interpretation, it is necessary to hold experience constant before the period of stimulation while varying it after this period. The experiments reported here adopt this design: animals are given theta driving before training in the alley on either a CRF schedule (food reward on every trial) or a PRF schedule (reward on a random $50 \%$ of trials), and finally the running response is extinguished. In this design, frustrative nonreward is encountered first during extinction for the CRF group but first during acquisition for the PRF group. The proactive effects of theta driving upon resistance to extinction should, therefore, according to Williams's (1988) hypothesis, take different directions in the two groups.

In fact, the hypothesis makes six highly specific predictions (Table 1) for this experimental design. If thetadriving stimulation is applied at 7.7 or $8.3 \mathrm{~Hz}$ and so (ex hypothesi) sensitizes the animal to nonreward, then the stimulated animals should be (1) less resistant to extinction in the CRF conditon (because of their greater reactivity to the nonreward first encountered during extinction itself), but (2) more resistant to extinction in the PRF condition (because of the greater counterconditioning of anticipatory frustration when nonreward is encountered during

Table 1

Predictions Tested in Experiments 1 and 2

\begin{tabular}{ccccc}
$\begin{array}{c}\text { Prediction } \\
\text { (See Text) }\end{array}$ & $\begin{array}{c}\text { Frequency of } \\
\text { Stimulation }\end{array}$ & $\begin{array}{c}\text { Training } \\
\text { Condition in } \\
\text { Acquisition }\end{array}$ & $\begin{array}{c}\text { Effect on } \\
\text { Rate of } \\
\text { Extinction }\end{array}$ & $\begin{array}{c}\text { Prediction } \\
\text { Confirmed? } \\
\text { (See Discussion) }\end{array}$ \\
\hline 1 & $7.7 \mathrm{~Hz}$ & $\mathrm{CRF}$ & Increase rate & $\checkmark$ \\
2 & $7.7 \mathrm{~Hz}$ & PRF & Decrease rate & $\checkmark$ \\
3 & $7.7 \mathrm{~Hz}$ & & Enhance PREE & $\checkmark$ \\
4 & $7.5 \mathrm{~Hz}$ & $\mathrm{CRF}$ & Decrease rate & $\times$ \\
5 & $7.5 \mathrm{~Hz}$ & PRF & Increase rate & $\checkmark$ \\
6 & $7.5 \mathrm{~Hz}$ & & Reduce PREE & $\checkmark$ \\
\hline
\end{tabular}

Note-CRF, continuous reinforcement; PRF, partial reinforcement. 
acquisition). Thus (3) the partial reinforcement effect (PREE) - that is, the difference between the rates of extinction in the CRF and PRF groups, respectively-should be magnified in the stimulated animals relative to unstimulated controls. Conversely, if the theta-driving stimulation is applied at $7.5 \mathrm{~Hz}$ and so (ex hypothesi) causes the animal to become tolerant of nonreward, then the stimulated animals should be (4) more resistant to extinction in the CRF condition (because of their lowered sensitivity to the nonreward first encountered then), but (5) less resistant to extinction in the PRF condition (because of reduced counterconditioning of anticipatory frustration during acquisition). Thus the PREE should now be diminished in the stimulated animals relative to unstimulated controls. Two further, more general predictions follow from these: namely, that the direction of the behavioral effects of theta driving should be opposite in sign for both the CRF and the PRF conditions, depending upon stimulation frequency ( 7.7 or $8.3 \mathrm{~Hz}$ vs. $7.5 \mathrm{~Hz}$ ).

Note also that this experimental design tests further the assumption that the FR5 leverpress paradigm used by Glazer (1974a, 1974b), Holt and Gray (1983b), and Williams and Gray (1996) is the functional equivalent of an alley PRF schedule. In our previous tests of this assumption (Williams et al., 1990), we argued from known differences between alley CRF and PRF schedules to the expected effects of experimental interventions on resistance to extinction of the FR5 response, and we showed that the latter responded to lesions to the septohippocampal system and anxiolytic drug treatment as does the running response acquired under a PRF rather than a CRF schedule. In the present experiments, the direction of inference is reversed. We have previously shown that preacquisition theta driving at 7.7 and $8.3 \mathrm{~Hz}$ proactively increases resistance to extinction of the FR5 response, whereas theta driving at $7.5 \mathrm{~Hz}$ decreases the resistance to extinction of this response (Holt \& Gray, 1983b; Williams \& Gray, 1996). We therefore predicted, from the postulated functional equivalence of the FR5 and PRF schedules, respectively, that we should see similar frequency-dependent effects upon the resistance to extinction of the running response if these stimulation regimes were applied to animals subsequently trained on a PRF (but not a CRF) schedule; these predictions are identical to Predictions 2 and 5 above.

The experiments reported here tested these predictions for 7.5- and 7.7-Hz stimulation frequencies. It was not felt necessary to investigate in addition the effects of $8.3-\mathrm{Hz}$ stimulation, since our previous studies (Williams \& Gray, 1996; Williams et al., 1989) have found these to be very similar to those of $7.7-\mathrm{Hz}$ stimulation, the latter being slightly greater. The contrast between 7.5 and $7.7 \mathrm{~Hz}$ is also of particular interest, given the extremely small amount by which these frequencies differ from one another. Replication of our previous findings (Holt, 1982; Williams \& Gray, 1996; Williams et al., 1989) that they nonetheless produce opposite effects on behavior would be important irrespective of the particular theoretical context used to predict the specific effects observed. An optimal design would be to allocate animals randomly to the two frequencies of stimulation within a single experiment. However, our previous work indicates that there are interactions, perhaps pheromonal in nature, between animals stimulated at different frequencies within a single experiment. In particular, we have failed to observe the expected effects of stimulation at $8.3 \mathrm{~Hz}$ when animals stimulated at $7.5 \mathrm{~Hz}$ are tested in the same experiment (Holt, 1982; Williams \& Gray, 1996). In the present study, therefore, we ran 7.5- and 7.7- $\mathrm{Hz}$ stimulated animals, and their respective unstimulated controls, in separate experiments, while however keeping every other aspect of the procedures constant. With a few exceptions (see Discussion) the methods of surgery and stimulation were closely similar to those used by Williams and Gray (1996), though the two reports describe experiments conducted in different laboratories.

In selecting the behavioral parameters of the experiments, we had regard to previous evidence concerning the effects of anxiolytic drugs. Such compounds appear to reduce anticipatory frustration rather generally (Gray, 1977). They also raise the threshold for septal driving of hippocampal theta selectively at frequencies close to $7.7 \mathrm{~Hz}$ (Gray \& Ball, 1970; McNaughton et al., 1977). This, indeed, was one of the observations that led to the initial formulation of the hypothesis (Gray, 1970) that the behavioral effects of theta driving at such frequencies would resemble those of exposure to frustrative nonreward. As part of their general capacity to antagonize the behavioral effects of anticipatory frustration, the anxiolytic drugs, given during acquisition of a running response, block the PREE. This effect is best obtained if trials are widely spaced - for example, at one trial a day (Feldon \& Gray, 1981; Feldon, Guillamon, Gray, De Wit, \& McNaughton, 1979) - which is consistent with other evidence (Gray, 1975; Mackintosh, 1974) that the influence of anticipatory frustration and its counterconditioning is greater, the longer the intertrial interval. Accordingly, we modeled our behavioral parameters on the one-trial-a-day paradigm used by Feldon and Gray (1981) to demonstrate blockade of the PREE by the benzodiazepine chlordiazepoxide.

\section{GENERAL METHOD}

The two experiments were run according to an identical timetable (Table 2) and identical procedures, except only for the frequency of stimulation (7.5 Hz in Experiment 1, 7.7 Hz in Experiment 2).

\section{Subjects and Surgery}

Male Sprague-Dawley rats, initially weighing $250-350 \mathrm{~g}$, were housed individually in wire mesh cages. Water was available ad lib throughout; prior to behavioral training, a food deprivation schedule was gradually introduced, on which, at least $1 \mathrm{~h}$ after the end of any experimental procedures that day, each animal was fed an individually adjusted amount intended to maintain body weight at $85 \%$ of the free-feeding level. All rats were implanted under Equithesin anesthesia with a recording electrode in the right dorsal subiculum and a stimulating electrode in the medial septal area as decribed previously (James, McNaughton, Rawlins, Feldon, \& Gray, 1977; Williams \& Gray, 1996). Bipolar twisted-wire electrodes were made from $0.15-\mathrm{mm}$ Teflon-coated stainless steel wires cut square at the tips; tip 
Table 2

Timetable of Experiments 1 and 2

\begin{tabular}{|c|c|c|}
\hline Stage & Procedures Implemented & Day(s) \\
\hline 1 & $\begin{array}{l}\text { Preparation of animals with septal } \\
\text { stimulating electrodes and subicular } \\
\text { recording electrodes }\end{array}$ & $1-14$ \\
\hline 2 & $\begin{array}{l}\text { Handling and introduction of food } \\
\text { deprivation }\end{array}$ & $15-29$ \\
\hline 3 & $\begin{array}{l}\text { Screening to determine the presence } \\
\text { or absence of theta driving }\end{array}$ & $30-31$ \\
\hline 4 & $\begin{array}{l}\text { Stimulation (fifteen } 6 \text {-sec trains } \\
\text { delivered every } 30 \mathrm{sec} \text {, at } 7.5 \\
\text { or } 7.7 \mathrm{~Hz} \text { ) }\end{array}$ & $32-42$ \\
\hline 5 & Pretraining in the alley & $43-45$ \\
\hline 6 & $\begin{array}{l}\text { Acquisition of CRF or PRF alley } \\
\text { running at one trial a day, for } 16 \text { days }\end{array}$ & $46-62$ \\
\hline 7 & $\begin{array}{l}\text { Extinction of CRF and PRF alley } \\
\text { running at one trial a day }\end{array}$ & $63-$ \\
\hline
\end{tabular}

Note-CRF, continuous reinforcement; PRF, partial reinforcement.

separation was $0.5 \mathrm{~mm}$ for the stimulating electrode and $2 \mathrm{~mm}$ for the recording electrode. Coordinates (skull level from bregma to lambda) for the septal electrode were: AP (from bregma) +0.6, L 3.9, $V$ (from skull surface) $5.5 \mathrm{~mm}$, the electrode being angled at $40^{\circ}$ from the median plane. Coordinates for the subicular electrode were: AP -6.0 , L 2.0 , V $5.0 \mathrm{~mm}$. The electrodes were fixed to the skull with dental cement anchored to bone screws. An uninsulated stainless steel wire wound round the bone screws served as a ground. The electrode and ground connections were brought via gold connecting pins to a pedestal (Plastic Products) fixed to the skull with dental cement. The rats were allowed 2-3 weeks to recover from surgery; during this time, they were intensively handled in groups in large bins filled with junk objects.

\section{Electrophysiological Procedures}

The theta-driving stimulation and recording methods have been described in detail (James et al., 1977). The animals were connected to the apparatus via a counterbalanced low-noise shielded cable (Plastic Products) fitted with a source follower. An optically isolated, constant-current, square-wave pulse generator (Farnell Instruments) delivered pulses of 0.5 -msec width at an interpulse interval of either $133 \mathrm{msec}(7.5 \mathrm{~Hz})$ or $130 \mathrm{msec}(7.7 \mathrm{~Hz})$. Recording was done on a Grass Model 79D polygraph fitted with 7P5B preamplifiers and a Tektronix 502A dual-beam storage oscilloscope; the oscilloscope was triggered by the pulse generator. Stimulation took place in opentopped chambers, $15 \times 25 \times 15 \mathrm{~cm}$. All animals were initially screened to determine whether they displayed driven theta waves, according to the criteria established by James et al. (1977). This period of stimulation was kept to a minimum (several seconds). The stimulation current was raised in small steps from $40 \mu \mathrm{A}$; if theta driving was not seen at $250 \mu \mathrm{A}$ or less, the animal was rejected from the study. Animals that showed theta driving were randomly allocated to the four groups making up the experiment (unstimulated vs. theta driving, orthogonally crossed with CRF vs. PRF). Animals allocated to the theta driving groups received, each day for 10 days, fifteen 6-sec stimulation trains (at a frequency of 7.5 or $7.7 \mathrm{~Hz}$, depending on the experiment) with a fixed 30 -sec interval between the offset of one train and the onset of the next, making a total of $90 \mathrm{sec}$ of stimulation over a session lasting approximately $9 \mathrm{~min}$. The stimulating current was set at $10 \%$ above the threshold for theta driving recorded on the screening day. The unstimulated controls were attached to the apparatus in an identical way in an identical adjacent chamber, during the periods when theta-driving animals were stimulated, but received no stimulation. Separate chambers were used for the theta-driving and unstimulated groups, in order to reduce the possibility of pheromonal interactions (Williams \& Gray, 1996).

\section{Behavioral Procedures}

Behavioral training began the day after the stimulation phase. The straight alley was made from aluminum, and was $22 \mathrm{~cm}$ wide, $33 \mathrm{~cm}$ high, and $1.7 \mathrm{~m}$ long, divided into start, run, and goal sections ( 20 , 124 , and $27 \mathrm{~cm}$ long, respectively) by aluminum doors between the startbox and run section (solenoid-operated) and at the entry to the goalbox (hand-operated guillotine). Start, run, and goal times were measured to the nearest $0.01 \mathrm{sec}$ by infrared photobeams located at the startbox door, $91 \mathrm{~cm}$ along the run section, and just in front of the foodcup at the rear of the goalbox. Pretraining, acquisition, and extinction followed the procedures of Feldon et al. (1979). Pretraining lasted 2 days: the animals explored the alley in groups of 4 (Day 1) or 2 (Day 2) with food scattered throughout the alley (Day 1) or in the goalbox only (Day 2). Acquisition lasted 16 days at 1 trial/day. On rewarded trials, there were twenty $45-\mathrm{mg}$ Noyes food pellets in the foodcup. Animals in the CRF condition had reward on every trial; those in the PRF condition received the following quasirandom schedule ( $\mathrm{R}=$ reward, $\mathrm{N}=$ nonreward): $\mathrm{R}, \mathrm{N}, \mathrm{R}, \mathrm{N}, \mathrm{R}, \mathrm{N}, \mathrm{R}$, $\mathrm{N}, \mathrm{R}, \mathrm{N}, \mathrm{N}, \mathrm{R}, \mathrm{R}, \mathrm{N}, \mathrm{N}, \mathrm{R}$. On $\mathrm{N}$ trials, the animal was confined to the goalbox for $30 \mathrm{sec}$. Extinction trials (1/day for 16 days in Experiment 1 and 26 days in Experiment 2) were identical to acquisition $\mathrm{N}$ trials. If, during extinction, an animal remained in any section of the alley for more than $100 \mathrm{sec}$, it was removed. Any animal remaining in any section of the alley for $100 \mathrm{sec}$ on 2 consecutive days was no longer run, and a score of $100 \mathrm{sec}$ was entered for each section for the remainder of the experiment. Animals were run in a quasirandom order with the restriction that each successive set of four contained one from each experimental condition; the order and approximate time of running remained constant over days.

\section{Statistics}

Start, run, and goal times were reciprocally transformed to improve homogeneity of variance and these "speeds" were subjected to analyses of variance (ANOVAs) separately for acquisition and extinction, with between-subjects factors of stimulation and-schedule and the within-subjects factor of days; trends over days were analyzed by using orthogonal polynomials; post hoc $t$ tests were based on pooled error terms from the ANOVAs.

\section{EXPERIMENT 1 Stimulation at $7.5 \mathrm{~Hz}$}

Of the 39 rats electrophysiologically screened, 9 failed to show good theta driving or recording. Of the remaining animals, the headstage became loose in 4 , and 2 failed to acquire the running response, giving final group sizes of 6 in each condition. The top trace of Figure 1 presents an example of the theta-driving response; and Table 3 gives mean stimulation currents. These did not differ significantly between the CRF and PRF conditions.

\section{Results}

Acquisition. There were no effects of stimulation upon performance during acquisition in any alley section. Acquisition of the running response was demonstrated by significant effects of days or its linear component $(p<.01)$ in every alley section. PRF-trained animals acquired the response more slowly than CRF animals, irrespective of stimulation condition, in both the run and goal sections [days $X$ schedule, $F(15,297)=2.37$ and 2.59 , respectively, $p<.01$ ] 

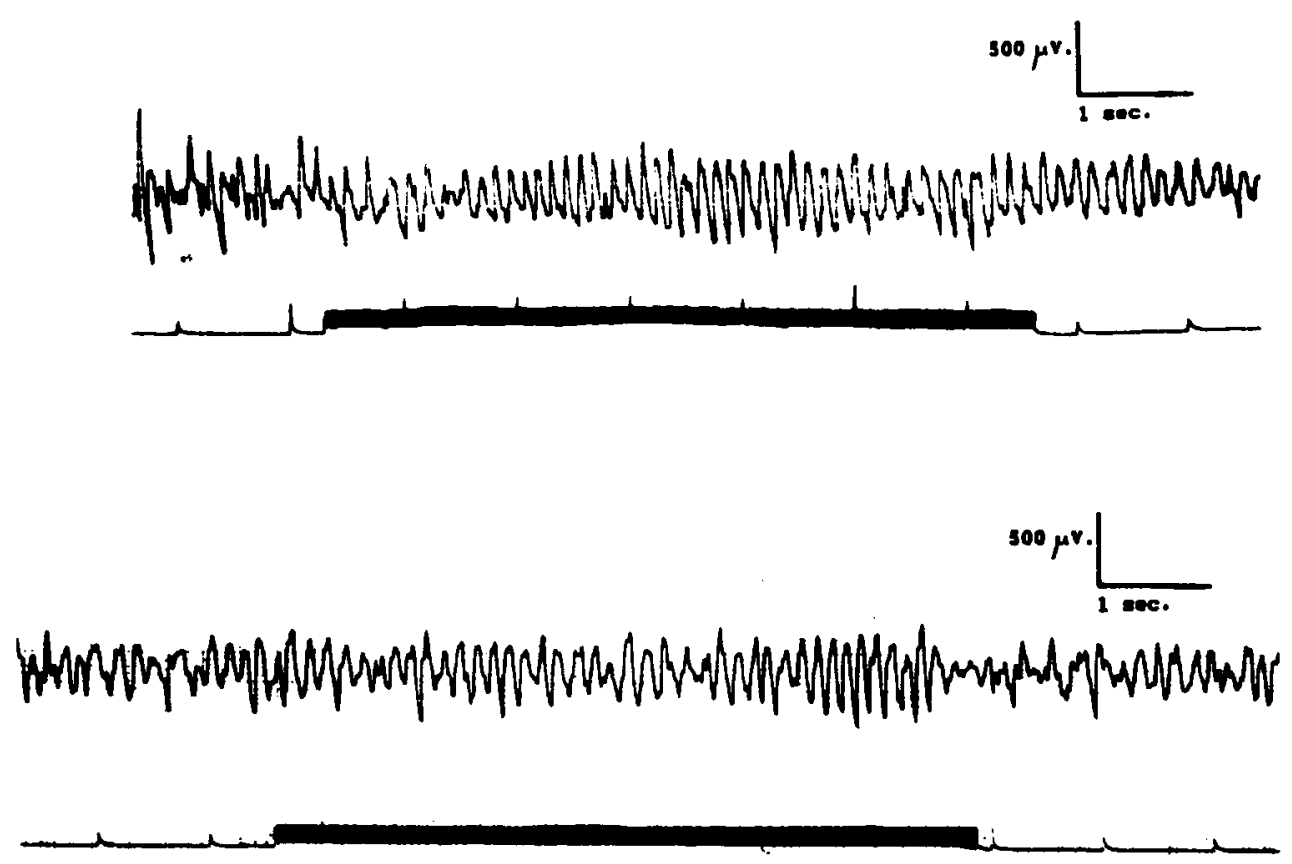

Figure 1. Examples of the 7.5-Hz (upper trace) and 7.7-Hz (lower trace) theta driving seen during the course of Experiments 1 and 2.

Extinction. The course of extinction is shown for each section of the alley in Figure 2. Significant effects of days $(p<.001)$ in every alley section confirmed that extinction took place.

In the start section there was a significant linear component in the days $\times$ schedule $\times$ stimulation interaction $[F(1,300)=5.42, p<.025]$. Comparisons of the linear coefficients by $t$ test (Table 4) confirmed the impression given by Figure 2 that a PREE (i.e., a significantly slower rate of extinction in the PRF relative to the CRF condition) had occurred in the unstimulated but not in the thetadriven groups. In addition, these comparisons showed that the stimulated PRF group had a significantly faster rate of extinction than the unstimulated PRF group. The apparently (Figure 2) greater resistance to extinction of the stimulated CRF group relative to the unstimulated CRF animals was not, however, significant (Table 4).

Graphically, performance in the run section was similar to that in the start section. However, there were no significant effects due to stimulation in this part of the alleythough the occurrence of a PREE overall was confirmed by the significant linear component in the days $\times$ schedule interaction $[F(1,300)=4.71, p<.05]$.

Table 3

Mean $( \pm S D)$ Stimulation Currents $(\mu \mathrm{A})$ Used in the Stimulation Phases of Experiments 1 (7.5-Hz Stimulation) and 2 (7.7-Hz Stimulation)

\begin{tabular}{ccc}
\hline Experiment & Stimulated CRF & Stimulated PRF \\
\hline $7.5 \mathrm{~Hz}$ & $71 \pm 27$ & $62 \pm 29$ \\
$7.7 \mathrm{~Hz}$ & $85 \pm 39$ & $59 \pm 35$ \\
\hline
\end{tabular}

Note-CRF, continuous reinforcement; PRF, partial reinforcement.
In the goal section there was a significant interaction between stimulation and schedule $[F(1,20)=4.51, p<.05]$. As shown in Figure 3, this interaction reflects significantly slower goal speeds in the unstimulated CRF group than in the unstimulated PRF group (a PREE) $[t(20)=$ $2.1, p<.05$ ], coupled with a nonsignificant tendency toward reversal of this effect in the stimulated CRF as opposed to the stimulated PRF group. The direction of the effect of stimulation differed as a function of reinforcement condition, goal speeds being increased in the CRF condition but decreased in the PRF condition; however, neither of these comparisons was significant on its own (by post hoc $t$ test).

\section{EXPERIMENT 2}

Stimulation at $7.7 \mathrm{~Hz}$

Of the 40 animals electrophysiologically screened, 8 failed to show theta driving, 4 lost their headstages, and 2 failed to acquire the running response, leaving the following final group sizes: CRF unstimulated, 6; PRF unstimulated, 5; CRF theta-driven, 8; PRF theta-driven, 7. An example of driven theta is presented in the lower trace of Figure 1; Table 3 presents mean stimulation currents, which did not differ significantly between the CRF and PRF conditions, nor from those employed in Experiment 1.

\section{Results}

Acquisition. Significant $(p<.05)$ effects of days or its linear component in each alley section confirmed acquisition of the running response. PRF-trained animals, irrespective of stimulation condition, had slower goal speeds 

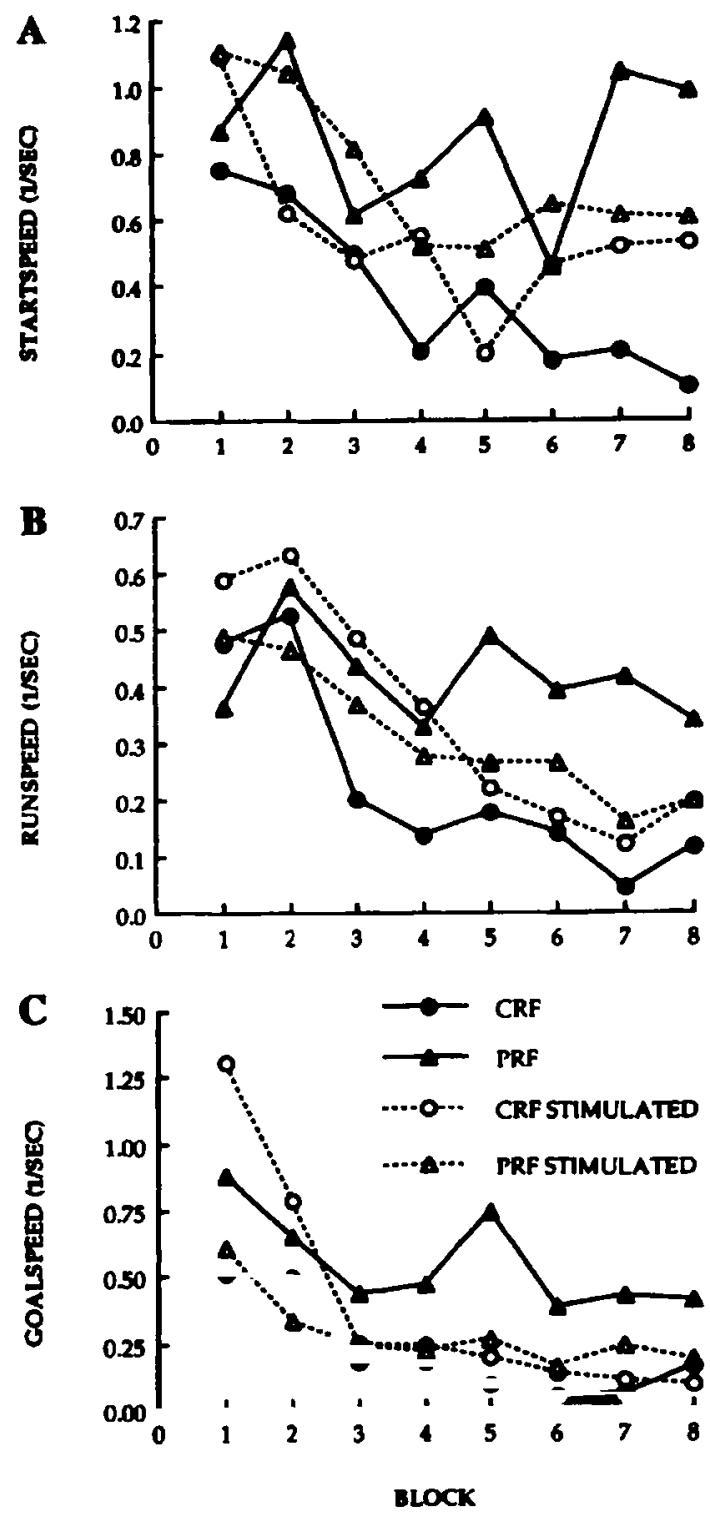

Figure 2. The course of extinction in the start (A), run (B), and goal (C) sections of the alley during the extinction phase of Experiment 1 . Filled circles, unstimulated continuously reinforced; filled triangles, unstimulated partially reinforced; open circles, stimulated continuously reinforced; open triangles, stimulated partially reinforced.

than did CRF animals, this difference increasing over the course of acquisition [days $\times$ schedule, $F(15,325)=6.7$, $p<.05]$. In the start and run sections, there were significant linear components in the days $\times$ schedule $\times$ stimulation interaction $[F(1,325)=2.1$ and $6.6, p<.05$ and .01 , respectively]. However, these effects were much less pronounced than those seen in extinction and did not appear to be systematic; accordingly, they are not reported here further (for details, see Snape, 1991). There were no significant differences between any of the groups at the end of acquisition in these sections.
Extinction. Highly significant $(p<.001)$ effects of days and the linear component of days confirmed that extinction took place in every alley section. The course of extinction is presented for the start and run sections in Figure 4. For ease of presentation, these data have been pooled into 2-day blocks. The reported analyses are based on all 26 days of extinction; however, additional analyses (Snape, 1991) using blocks instead of days confirmed that this caused no substantial changes in the statistical results.

In the start section there was a significant interaction between days, stimulation, and schedule $[F(25,549)=$ $2.27, p<.01$ ], and a highly significant linear component of this interaction $[F(1,549)=26.5, p<.001]$. Comparisons of the linear coefficients by $t$ test (Table 4) demonstrated that the stimulated animals extinguished significantly faster than their unstimulated controls in the CRF condition, and significantly slower than the controls in the PRF condition, thus demonstrating an enhanced PREE. All these effects became apparent late in extinction. Similar effects emerged in the run section: days $\times$ stimulation $\times$ schedule $[F(25,549)=4.35, p<.01 ;$ linear component of this interaction, $F(1,549)=71.02, p<.001]$. The $t$ tests comparing the linear coefficients (Table 4) give rise to the same conclusions as those for the start data: stimulated animals extinguished significantly more quickly in the CRF condition, and significantly more slowly in the PRF condition, than did unstimulated controls, thus showing an enhancement of the PREE. Again, these effects are particularly pronounced late in extinction.

The goal speeds showed no significant effects relating to either schedule or stimulation.

\section{DISCUSSION}

The major results of the two experiments are summarized in Table 1. In general, they are in good agreement with the predictions outlined in the introduction. Thus, in Experiment 2, preacquisition stimulation at $7.7 \mathrm{~Hz}$ de-

Table 4

Analysis of Linear Trend Data From Experiments 1 (Start Speed) and 2 (Start Speed and Run Speed)

\begin{tabular}{lccc}
\hline & CRF & PRF & $t$ \\
\hline & Experiment 1 $(7.5 \mathrm{~Hz})$ : Start Speed & \\
Unstimulated & -0.0397 & -0.0105 & $2.66^{*}$ \\
Stimulated & -0.0309 & -0.0349 & n.s. \\
$t$ & n.s. & $2.22^{*}$ & \\
& Experiment $2(7.7 \mathrm{~Hz}):$ Start Speed & \\
Unstimulated & -0.0344 & -0.0591 & $6.90 \dagger$ \\
Stimulated & -0.043 & -0.0206 & $2.32^{*}$ \\
$t$ & $6.1 \dagger$ & $10.4 \dagger$ & \\
& Experiment $2:(7.7 \mathrm{~Hz}):$ Run Speed & \\
Unstimulated & -0.0114 & -0.0262 & $11.40 \dagger$ \\
Stimulated & -0.0198 & -0.0073 & $6.46 \dagger$ \\
$t$ & $9.62 \dagger$ & $14.5 \dagger$ & \\
\hline
\end{tabular}

Note-The table shows results of logical comparisons made post hoc by performing $t$ tests on the linear trend coefficients of the relevant groups. CRF, continuous reinforcement; PRF, partial reinforcement. ${ }^{*} p<.01$. ${ }^{+} p<.0001$. n.s., not significant. 


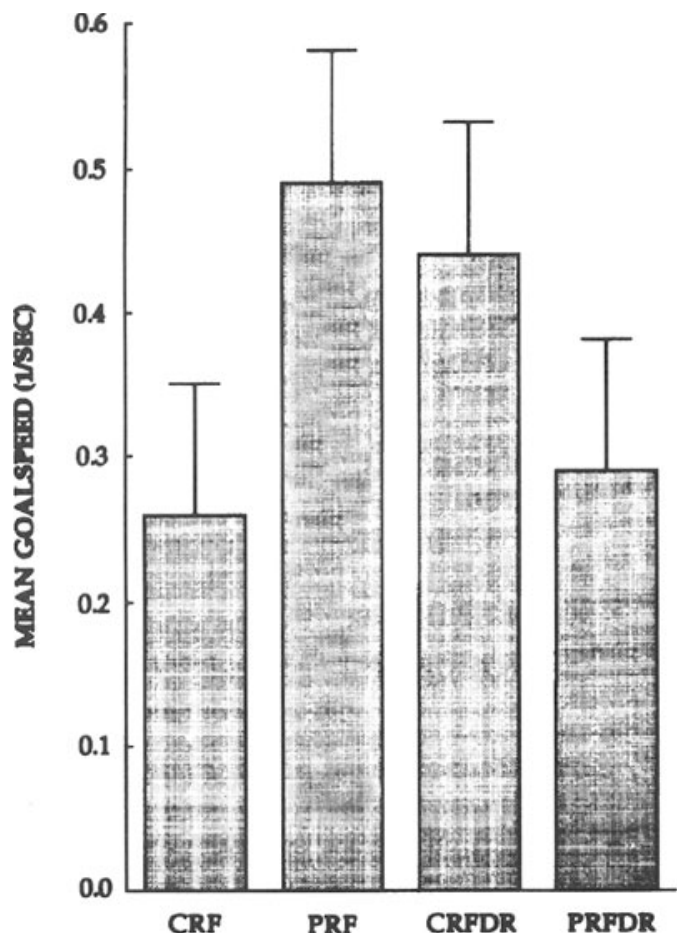

Figure 3. Mean speeds in the goal section of the alley in Experiment 1. CRF, unstimulated continuously reinforced; PRF, unstimulated partially reinforced; CRFDR, stimulated continuously reinforced; PRFDR, stimulated partially reinforced.

creased resistance to extinction in CRF-trained animals in both the start and the run section, confirming Prediction 1; increased resistance to extinction in PRF-trained animals, confirming Prediction 2; and thus enhanced the PREE, confirming Prediction 3. In Experiment 1, preacquisition stimulation at $7.5 \mathrm{~Hz}$ decreased resistance to extinction in PRFtrained animals, significantly so in the start section, and abolished the PREE in the goal section, confirming Predictions 5 and 6 ; stimulation at this frequency did not, however, increase resistance to extinction in the CRF condition (Prediction 4), though a nonsignificant trend in this direction was observed in every section (Figures 2 and 3 ). When the two experiments are considered together, it is also clear that the effects of theta-driving stimulation at 7.5 and $7.7 \mathrm{~Hz}$, respectively, were opposite in sign for the PRF condition, confirming Prediction 8, and different from each other for the CRF condition, partially confirming Prediction 7 . These remarkable differences between the behavioral effects of theta driving at such closely adjacent frequencies also confirm our previous observations made in using the FR5 paradigm (Holt, 1982; Williams \& Gray, 1996). Other studies, focusing on hippocampal long-term potentiation and depression, have similarly different or even opposing results at different frequencies of stimulation (Christie \& Abraham, 1992; Zhuo, Kandel, \& Hawkins, 1994), but the distance between frequencies used was much greater (e.g., 1 vs. 5 vs. $15 \mathrm{~Hz}$ in Christie and Abraham's report) than in our experiments. Finally, our results confirm the assump- tion (Williams et al., 1990), on which many of our arguments are based, that the FR5 paradigm resembles an alley PRF schedule, in that FR5 acquisition involves exposure to intermittent reinforcement and therefore to frustrative nonreward. Thus, just as we have previously reported that preacquisition theta driving at $7.7 \mathrm{~Hz}$ increases the resistance to extinction of the FR5 response, while such stimulation at $7.5 \mathrm{~Hz}$ decreases it (Holt, 1982; Holt \& Gray, 1983b; Williams \& Gray, 1996), so we have found here that animals trained on a PRF schedule in the alley show increased resistance to extinction after pre-acquisition stimulation at $7.7 \mathrm{~Hz}$ (Experiment 2) but decreased resistance to extinction after such stimulation at $7.5 \mathrm{~Hz}$ (Experiment 1); and neither of these effects was observed in animals trained on a CRF schedule. These findings therefore confirm our interpretation of other data, obtained with quite different techniques (Williams et al., 1990).

The extent of agreement between our predictions and our observations is, then, remarkably good. Apart from
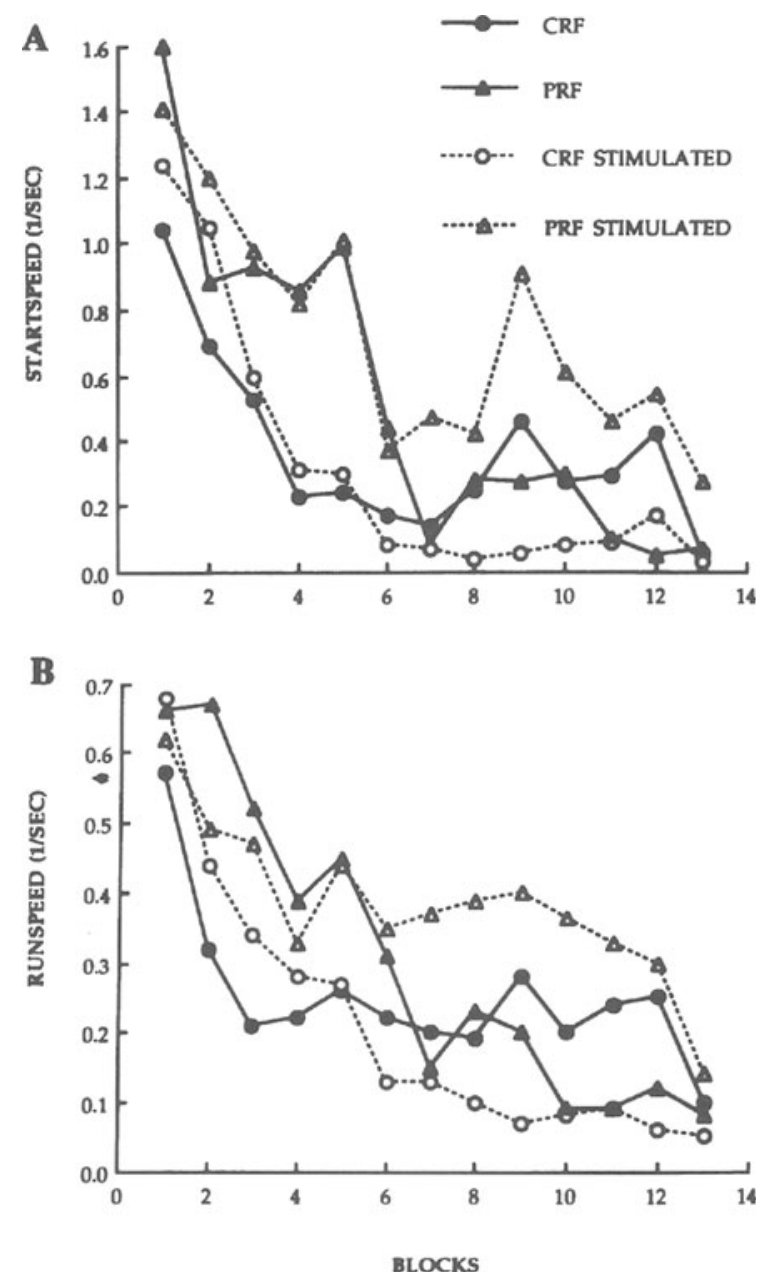

Figure 4. The course of extinction in the start (A) and run (B) sections of the alley during the extinction phase of Experiment 2. Filled circles, unstimulated continuously reinforced; filled triangles, unstimulated partialy reinforced; open circles, stimulated continuously reinforced; open triangles, stimulated partially reinforced. 
Williams's (1988) model, we know of no other hypothesis concerning the behavioral functions of hippocampal theta from which these observations could have been predicted, nor even from which a credible account of them could be derived post hoc. The hypotheses that see a role for theta in voluntary movement (Vanderwolf, 1969) or spatial mapping (O'Keefe \& Nadel, 1978) have no natural application to this type of experiment. First, it is difficult to derive from these hypotheses any way in which stimulationinduced increases (or decreases) either in the tendency to move or in the ability to generate and use spatial maps could differentially alter running behavior during extinction as a function of the intervening schedule of reinforcement. Second, any such framework of explanation would need to account also for the effects described by Williams and Gray (1996), from which the predictions tested here were derived. Those effects were obtained in an operant conditioning paradigm that, in comparison with the present alley task, places low demands on spatial analysis and different demands on voluntary movement. In contrast, the explanatory framework adopted here transfers naturally between different tasks, provided that one has correctly interpreted equivalences between different schedules of reinforcement (Williams et al., 1990; see the introduction to the present paper).

The hypothesis of a role in the consolidation of memory (Landfield, 1977) is also, in its simplest form, inapplicable, since all behavioral experience in these experiments occurred after the period of septal stimulation was over; thus, at the time of stimulation, there was no relevant memory to consolidate. We cannot, it is true, rule out a proactive change in general memorial processing, with subsequent effects on extinction of the running response. The process of extinction clearly requires fresh learning (viz., that running to the goal is no longer ever followed by reward), allied probably to the necessity then to retrieve (in the startbox) the currently correct memory (running no longer followed by reward), rather than the previously correct one (running always, for CRF, or sometimes, for PRF, followed by reward). However, considerable theoretical elaboration would be required in order for one to show how any change in relevant memorial processes might affect extinction differentially, depending on acquisition schedule and stimulation frequency.

In the absence of such elaboration, and given the coherence of the present findings with those reported by Williams and Gray (1996), the experiments reported here serve also to discount any application of Landfield's (1977) consolidation hypothesis to the finding reported by Williams and Gray (1996, Experiment 3 ) that the effects of $8.3-\mathrm{Hz}$ theta driving on the resistance to extinction of the FR5 response differ, depending on whether stimulation is applied before acquisition or between acquisition and extinction. Within Landfield's framework, this result might have been interpreted as showing that stimulation after acquisition and before extinction affects the latter by modifying memories stored during acquisition. Given the present results, however, it is more likely that the critical factor lies in the circumstances surrounding the first en- counter with nonreward after the period of stimulation: during acquisition (as when stimulation was delivered before FR5 acquisition in Williams and Gray's Experiment 3, and before PRF training in the present experiments) or during extinction (as when stimulation was delivered after FR5 acquisition in the Williams and Gray experiment, and before CRF training here). A further way in which the present results clarify interpretation of Williams and Gray's (1996) Experiment 3 concerns the length of time elapsing between stimulation and the critical behavioral observations during extinction. In the Williams and Gray experiment, this was greater when stimulation was applied preacquisition than when it was applied between acquisition and extinction, leaving open the possibility that theta driving has long-term effects that change with the passage of time, independently of behavioral experience. The present experiments rule this possibility out, since the time between stimulation and extinction was identical for the CRF and PRF groups.

Taken together, therefore, the results reported here and elsewhere (Holt \& Gray, 1983b; Williams \& Gray, 1996) make it clear that theta-driving septal stimulation has proactive effects on behavior that can become manifest long after the stimulation is over (more than $\mathbf{4 0}$ days later in the present Experiment 2); but that the way in which these effects (on resistance to extinction) become manifest can be modified by behavioral experience (during acquisition) subsequent to the period of stimulation. As emphasized also by Williams and Gray (1996), this modification of stimulation effects on extinction by behavioral experience during acquisition must be distinguished from artifactual changes in measured extinction behavior due merely to effects of the stimulation on the behavioral baseline for extinction that is constituted by asymptotic acquisition performance. In the present experiments, this asymptote was unaffected by septal stimulation.

The line of research to which our work belongs commenced in the alley (Gray, 1970) but subseqently moved to the operant FR5 paradigm introduced by Glazer (1974a, 1974b). The present experiments bring us back to the alley, allowing us to make contact with the considerable body of data that has been accumulated since 1970 on the neurobiology of the PREE measured in this apparatus. These data indicate, inter alia, that the PREE is weakened after damage to the septohippocampal system (SHS), both septal (e.g., Feldon \& Gray, 1979; Henke, 1977) and hippocampal (e.g., Feldon, Rawlins, \& Gray, 1985; Rawlins, Feldon, \& Gray, 1980); after damage to the dorsal ascending noradrenergic bundle (DANB) (Owen, Boarder, Gray, \& Fillenz, 1982), which conveys afferents from the locus coeruleus to the SHS; and after systemic administration of anxiolytic drugs, including barbiturates (e.g., Feldon et al., 1979) and benzodiazepines (e.g., Feldon \& Gray, 1981). These different observations are almost certainly connected. In particular, release of noradrenaline (NA) from terminals of the DANB within the hippocampal formation facilitates neuronal impulse traffic within the latter structure (Segal, 1977); the anxiolytic drugs reduce such NA release (Corrodi, Fuxe, Lidbrink, \& Olson, 1971; McNaughton \& 
Mason, 1980, for review); and the latter action apparently underlies the capacity of these drugs to increase the threshold for septal driving of hippocampal theta at $7.7 \mathrm{~Hz}$ (Gray, McNaughton, James, \& Kelly, 1975; McNaughton et al., 1977). Thus, reduction in the PREE appears to follow from interventions that reduce the functional effectiveness of the SHS, whether by direct lesion, by lesion of its noradrenergic afferents, or by the administration of drugs that reduce transmission in these afferents. In the present experiments, reduction of the PREE was a longterm consequence of theta driving at $7.5 \mathrm{~Hz}$, suggesting that this stimulation regime may in some way compromise the normal functioning of the SHS; while stimulation at $7.7 \mathrm{~Hz}$ had the opposite effect, suggesting that this regime may in some way enhance normal septohippocampal function.

With regard to the former suggestion - that $7.5-\mathrm{Hz}$ stimulation proactively impairs function in the SHS - one way in which this could occur is by direct lesion of the septal region where the electrode is implanted. There are three reasons to discount this possibility. First, whereas in our earlier experiments (Holt \& Gray, 1983b; Williams \& Gray, 1996), animals with poor theta driving were allocated to be unstimulated controls and thus might have sustained slightly different damage from electrode implantation than did stimulated animals, in the present experiment good theta drivers were randomly allocated to the stimulation and control groups; and threshold driving currents in the two groups did not differ significantly. Second, when 7.7- $\mathrm{Hz}$ theta-driving stimulation was applied via lateral septal electrodes before training in a multitrial PREE paradigm, the effects seen (Williams et al., 1989) were similar to those observed here with a medial septal placement; yet the effects on the PREE of lateral and medial septal electrolytic lesions, respectively, differ considerably from each other (Feldon \& Gray, 1979a, 1979b). Third, there is no reason to suppose that any lesion, whether sustained from electrode implantation or from stimulation itself, should have differed between the animals stimulated at 7.5 and $7.7 \mathrm{~Hz}$; yet the behavioral effects of these two frequencies of stimulation were diametrically opposed. If any difference in lesion extent were due to stimulation, this should theoretically be greater for the higher frequency; yet it is stimulation at 7.5 , not $7.7 \mathrm{~Hz}$, whose effects resemble those of a lesion.

With regard to the latter suggestion--that $7.7-\mathrm{Hz}$ stimulation proactively enhances function in the SHS - such an effect may perhaps be mediated by changes in noradrenergic activity. We have previously reported that thetadriving stimulation at $8.3 \mathrm{~Hz}$, according to the regime used by Holt and Gray (1983b; see Williams et al., 1989) and shown by Williams and Gray (1996) to be functionally equivalent to stimulation at $7.7 \mathrm{~Hz}$, leads to a long-term increase in the activity of tyrosine hydroxylase $\mathrm{TH}$, the rate-limiting enzyme for catecholamine synthesis) in the hippocampus; and that the time at which elevated hippocampal TH activity was observed corresponded well with that of the observed increase in resistance to extinction (Graham-Jones, Holt, Gray, \& Fillenz, 1985). It is possible, therefore, that enhanced noradrenergic input to the hippo- campal formation consequent upon 7.7- or $8.3-\mathrm{Hz}$ septal stimulation underlies the behavioral effects observed in the present experiments.

In experiments related to this hypothesis, we have recently demonstrated that a single systemic injection of nicotine similarly causes a long-term increase (observed over the period 21-42 days after drug administration) in hippocampal TH activity. This increase appears to be secondary to enhanced expression of TH mRNA and induction of $\mathrm{TH}$ in the locus coeruleus, followed probably by slow axonal transport to the terminal regions of the DANB, including the hippocampus (Mitchell, Brazell, Joseph, Alavijeh, \& Gray, 1989; Mitchell, Smith, Joseph, \& Gray, 1993). The resulting elevation in hippocampal TH activity was, furthermore, accompanied by an increase in the hippocampal NA release stimulated by a second, acute nicotine challenge (Mitchell et al., 1993), perhaps indicative of facilitated impulse traffic in the hippocampal formation (Segal, 1977). These observations provide a new way to test the possibility that the proactive effects of 7.7$\mathrm{Hz}$ theta driving on the PREE are mediated by enhanced functioning of the noradrenergic innervation of the hippocampus. If this hypothesis is correct, systemic injections of nicotine should proactively increase the PREE in the same manner as does $7.7-\mathrm{Hz}$ septal stimulation. We have recently tested this prediction by training animals on a CRF or PRF alley-running schedule after a single subcutaneous injection of $0.8-\mathrm{mg} / \mathrm{kg}$ nicotine, with acquisition and extinction timed to occur during the period of elevated noradrenergic function. The PREE was significantly increased, as predicted, in two separate experiments, one at one trial a day (the same paradigm as used here) and the other at six trials a day (Grigoryan \& Gray, in press; see Gray et al., 1994). Moreover, pretreatment with seven daily injections of nicotine $(0.8 \mathrm{mg} / \mathrm{kg})$ had the same proactive effect on the PREE as did a single injection, and to the same degree, paralleling the similarity of effect seen in measurements of TH activity in response to these two drug regimes (Mitchell et al., 1989; Mitchell et al., 1993).

A link between this proactive enhancement of the PREE by nicotine and changes in hippocampal electrophysiology, respectively, is suggested by further unpublished experiments, carried out in our group by S. Hamid, G. Dawe, and J. Stephenson (personal communication, April 1995). Using anesthetized rats, these workers measured the effects of a challenge dose of nicotine $(0.4 \mathrm{mg} / \mathrm{kg})$ on the slope of the excitatory postsynaptic potential (EPSP), recorded in the dentate gyrus in response to perforant path stimulation. Their data show that the slope of the EPSP is enhanced by the challenge dose of nicotine, which is consistent with previous reports, first, that systemic nicotine causes hippocampal release of noradrenaline (Mitchell et al., 1993), and second, that bath application of noradrenaline to hippocampal slices potentiates the response of dentate granule cells to perforant path stimulation (Stanton, Mody, \& Heinemann, 1989). Furthermore, preliminary results indicate that this effect of acute nicotine on the EPSP slope was augmented by treatment with systemic nicotine $(0.8 \mathrm{mg} / \mathrm{kg}$ daily for 7 days $) 3$ weeks previ- 
ously. Thus, the neural pathways by which septal thetadriving stimulation (at 7.7 or $8.3 \mathrm{~Hz}$ ) and systemic nicotine, respectively, proactively enhance the PREE may be essentially the same; and both may involve (1) increased intrahippocampal noradrenergic response to appropriate challenges (nonreward, acute systemic nicotine), and (2) increased hippocampal response to inputs from cortical systems via the perforant path. However, even if these inferences prove to be along the right lines, it remains obscure how theta-driving stimulation is able to affect $\mathrm{TH}$ activity in fibers of the DNAB and why such an effect should depend so critically and sensitively on stimulation frequency.

\section{REFERENCES}

AMSEL, A. (1962). Frustrative nonreward in partial reinforcement and discrimination learning: Some recent history and a theoretical extension. Psychological Review, 69, 306-328.

AMSEL, A. (1992). Frustration theory. Cambridge: Cambridge University Press.

Christie, B. R., \& Abraham, W. C. (1992). Priming of associative long-term depression in the dentate gyrus by theta frequency synaptic activity. Neuron, 9, 79-84.

Corrodi, H., Fuxe, K., Lidbrink, P., \& Olson, L. (1971). Minor tranquilizers, stress and central catecholamine neurons. Brain Research, 29, $1-16$

Deupree, D., CopPock, W., \& Willer, H. (1982). Pretraining septal driving of hippocampal rhythmic slow activity facilitates acquisition of visual discrimination. Journal of Comparative \& Physiological Psychology, 96, 557-562.

FELDON, J., \& GRAY, J. A. (1979a). Effects of medial and lateral septal lesions on the partial reinforcement extinction effect at one trial a day. Quarterly Journal of Experimental Psychology, 31, 653-674.

FELDON, J., \& GRAY, J. A. (1979b). Effects of medial and lateral septal lesions on the partial reinforcement extinction effect at short inter-trial intervals. Quarterly Journal of Experimental Psychology, 31, 675-690.

FELDON, J., \& GRAY, J. A. (1981). The partial reinforcement extinction effect after treatment with chlordiazepoxide. Psychopharmacology, 73, 269-275

Feldon, J., Guillamon, A., Gray, J. A., De Wit, H., \& McNAUGHTON, N. (1979). Sodium amylobarbitone and responses to nonreward. Quarterly Journal of Experimental Psychology, 31, 19-50.

Feldon, J., Rawlins, J. N. P., \& Gray, J. A. (1985). Fornix-fimbria section and the partial reinforcement extinction effect. Experimental Brain Research, 58, 435-439.

GLAZER, H. I. (1974a). Instrumental conditioning of hippocampal theta and subsequent response persistence. Journal of Comparative \& Physiological Psychology, 86, 267-273.

GLAZER, H. I. (1974b). Instrumental response persistence following induction of hippocampal theta frequency during fixed-ratio responding in rats. Journal of Comparative \& Physiological Psychology, 86, 1156-1162.

Graham-Jones, S., Holt, L., Gray, J. A., \& Fillenz, M. (1985). Lowfrequency septal stimulation increases tyrosine hydroxylase activity in the hippocampus. Pharmacology, Biochemistry \& Behavior, 23, 489-493.

GRAY, J. A. (1970). Sodium amobarbital, the hippocampal theta rhythm and the partial reinforcement extinction effect. Psychological Review, $77,465-480$

GraY, J. A. (1972). Effects of septal driving of the hippocampal theta rhythm on resistance to extinction. Physiology \& Behavior, 8, 481-490.

GraY, J. A. (1975). Elements of a two-process theory of learning. London: Academic Press.

GraY, J. A. (1977). Drug effects on fear and frustration: Possible limbic site of action of minor tranquillizers. In L. L. Iversen, S. D. Iversen, \& S. H. Snyder (Eds.), Handbook of psychopharmacology: Vol. 8. Drugs, neurotransmitters and behavior (pp. 433-529). New York: Plenum.

GRAY, J. A. (1982). The neuropsychology of anxiety: An enquiry into the function of the septo-hippocampal system. Oxford: Oxford University Press.

Gray, J, A., \& Ball, G. G. (1970, June 5). Frequency-specific relation between hippocampal theta rhythm, behavior and amobarbital action. Science, 168, 1246-1248.

Gray, J. A., MCNaughton, N., James, D. T. D., \& Kelly, P. H. (1975). Effect of minor tranquillizers on hippocampal theta rhythm mimicked by depletion of forebrain noradrenaline. Nature, 258, 424-425.

Gray, J. A., Mitchell, S. N., Joseph, M. H., Grigoryan, G. A., DAWE, S., \& HoDGES, H. (1994). Neurochemical mechanisms mediating the behavioral and cognitive effects of nicotine. Drug Development Research, 31, 3-17.

Grigoryan, G., \& Gray, J. A. (in press). A single dose of nicotine proactively enhances the partial reinforcement extinction effect in the rat. Psychobiology.

HENKE, P. G. (1977). Dissociation of the frustration effect and the partial reinforcement extinction effect after limbic lesions in rats. Journal of Comparative \& Physiological Psychology, 91, 1032-1038.

HoLT, L. (1982). Proactive behavioral effects of septal stimulation in the rat. Unpublished doctoral dissertation, Oxford University.

Holt, L., \& Gray, J. A. (1983a). Proactive behavioral effects of thetablocking septal stimulation in the rat. Behavioral \& Neural Biology, 39, 7-21.

HoLt, L., \& Gray, J. A. (1983b). Septal driving of the hippocampal theta rhythm produces a long-term, proactive and non-associative increase in resistance to extinction. Quarterly Journal of Experimental Psychology, 35B, 97-118.

Holt, L., \& Gray, J. A. (1985). Proactive behavioral effects of thetadriving septal stimulation on conditioned suppression and punishment in the rat. Behavioral Neuroscience, 99, 60-74.

James, D. T., McNaughton, N., Rawlins, J, N. P., Feldon, J., \& GRAY, J. A. (1977). Septal driving of hippocampal theta rhythm as a function of frequency in the free-moving male rat. Neuroscience, $\mathbf{2}$, $1007-1017$

LANDFIELD, P. W. (1977). Different effects of post-trial driving or blocking of the theta rhythm on avoidance learning in rats. Physiology \& Behavior, 18, 439-445.

MaCKINTOSH, N. J. (1974). The psychology of animal learning. New York: Academic Press.

McNaughton, N., James, D. T. D., Stewart, J., Gray, J. A., Valero, I., \& Drewnowski, A. (1977). Septal driving of hippocampal theta rhythm as a function of frequency in the male rat: Effects of drugs. Neuroscience, 2, 1019-1027.

MCNaughton, N., \& MASON, S. T. (1980). The neuropsychology and neuropharmacology of the dorsal ascending noradrenergic bundlea review. Progress in Neurobiology, 14, 157-219.

Mitchell, S. N., Brazell, M. P., Joseph, M. H., Alavijeh, M. S., \& GraY, J. A. (1989). Regionally specific effects of acute and chronic nicotine on rates of catecholamine and indoleamine synthesis in rat brain. European Journal of Pharmacology, 167, 311-322.

Mitchell, S. N., Smith, K. M., JosePh, M. H., \& Gray, J. A. (1993). Increases in tyrosine hydroxylase messenger RNA in the locus coeruleus after a single dose of nicotine are followed by time-dependent increases in enzyme activity and noradrenaline release. Neuroscience, 56, 989-997.

O' KeEFE, J., \& NADEL, L. (1978). The hippocampus as a cognitive map. Oxford: Oxford University Press, Clarendon Press.

Owen, S., Boarder, M., Gray, J. A., \& Fillenz, M. (1982). Effects of lateral and medial septal lesions on response suppression mediated by response-contingent and response-independent shock. Physiological Psychology, 10, 145-152.

Rawlins, J. N. P., Feldon, J., \& Gray, J. A. (1980). The effects of hippocampectomy and of fimbria section upon the partial reinforcement extinction effect in rats. Experimental Brain Research, 38, 273-283.

SEGAL, M. (1977). The effects of brainstem priming stimulation on interhemispheric hippocampal responses in the awake rat. Experimental Brain Research, 29, 553-565.

SNAPE, M. (1991). An investigation of the effects of proactive theta driving septal stimulation on tolerance for stress. Unpublished doctoral dissertation, University of London.

Stanton, P. K., Mody, I., \& Heinemann, U. (1989). A role for $N$-methyl- 
D-aspartate receptors in norepinephrine-induced long-lasting potentiation in the dentate gyrus. Experimental Brain Research, 77, 517-530. STUMPF, C. (1965). Drug action on the electrical activity of the hippocampus. International Review of Neurobiology, 8, 77-138.

VANDERWOLF, C. H. (1969). Hippocampal electrical activity and voluntary movement in the rat. Electroencepholography \& Clinical Neurophysiology, 26, 407-418.

Wetzel, W., OtT, T., \& Matthies, H. (1977). Post-training hippocampal rhythmic slow activity ("theta") elicited by medial septal stimulation improves memory consolidation in rats. Behavioral Biology, 21, 32-40.

Williams, J. H. (1988). An investigation of long-term pro-active nonassociative mechanisms by which theta-driving septal stimulation alters behaviour in rats. Unpublished doctoral dissertation, Oxford University.

Williams, J. H., \& GRAY, J. A. (1996). Dependence of the proactive behavioral effects of theta-driving septal stimulation on stimulation frequency and behavioral experience: 1. Leverpress experiments. Psychobiology, 24, 9-21.
Williams, J. H., Gray, J. A., Sinden, J. D., Buckland, C., \& RaWlINS, J. N. P. (1990). Effects of GABAergic drugs, fornicotomy, hippocampectomy and septal lesions on the extinction of a discrete-trial fixed ratio 5 leverpress response. Behavioral Brain Research, 41, 129-150.

Williams, J. [H.], Gray, J. A., Snape, M., \& Holt, L. (1989). Longterm effects of septohippocampal stimulation on behavioural responses to anxiogenic stimuli. In P. Tyrer, (Ed.), Psychopharmacology of anxiety (British Association for Psychopharmacology Monograph No. 11, pp. 80-108). Oxford: Oxford University Press.

Zhuo, M., Kandel, E. R., \& HaWkins, R. D. (1994). Nitric oxide and cGMP can produce either synaptic depression or potentiation depending on the frequency of presynaptic stimulation in the hippocampus. NeuroReport, 5, 1033-1036.

(Manuscript received April 17, 1995; revision accepted for publication July 11,1995 .) 